\title{
Factors Affecting Students' Self-Efficacy Beliefs in Moroccan Higher Education
}

\author{
Otmane Omari ${ }^{1}$, Mohammed Moubtassime ${ }^{2}$, Driss Ridouani ${ }^{1}$
}

\author{
${ }^{1}$ Moulay Ismail University \\ ${ }^{2}$ Sidi Mohamed Ben Abdellah University
}

Correspondence concerning this article should be addressed to Otmane Omari, Department of English, Moulay Ismail University, Faculty of Letters and Humanities, B.P 11202 Zaytoun, Meknes, Morocco.

E-mail: o.omari@edu.umi.ac.ma

\begin{abstract}
Self-efficacy, or confidence in one's ability to do a task, is a key element that affects students' motivation and performance. For that reason, the main purpose of this study was to collect specific information about students' self-efficacy and factors affecting it. This includes comparing the differences between three Moroccan universities representing public and private institutions in terms of students' self-efficacy. A sample of 365 undergraduate students responded to the questionnaire on self-efficacy for self-regulated learning on a 5-point Likert scale. The findings demonstrate that students' level of self-efficacy is moderate. With regard to the differences between the three universities, a slight difference was found in favor of the private one. Meanwhile, third-year students reported greater self-efficacy than first and second-year students. However, no statistically significant differences were found between male and female students. More importantly, the results reveal that students' living circumstances during the academic year and their initial motive behind enrolling in university affected their self-efficacy beliefs. Overall, this study provides teachers and practitioners with insights about self-efficacy that could be used to promote students' success in Moroccan universities.
\end{abstract}

Keywords: self-efficacy, self-regulated learning, higher education, student beliefs, EFL, Morocco

\section{Introduction}

A growing body of research, such as Schunk (1991), discussed academic motivation in terms of self-efficacy. The concept of self-efficacy was interpreted by Bandura (2010) as the beliefs in one's abilities that he/she can perform such tasks or activities. Since being first introduced by Bandura (1977), self-efficacy has been considered as a significant predictor of motivation. This is to say that understanding the motivation of students toward learning is more relevant through assessing their self-efficacy (Matthews, 2010). For instance, Pintrich (1994) confirmed that students who believe in their abilities participate in tasks that are hard and use deeper processing strategies than students who have low ability beliefs.

With regard to this argumentation, the question arises: Why do some students improve their self-beliefs while others always question their beliefs? Bandura (2010), in particular, provided four main sources that affect students' self-efficacy. The most influential source according to him is mastery experience. That is, the ability to develop strong beliefs from previous successful experiences. For instance, success in performing a task improves one's beliefs in his/her abilities; however, failure doing that task weakens the feeling of ability beliefs. The other self-efficacy sources according to Bandura are:

- Social modeling (vicarious experience), which has to do with the ability of students to learn new things while observing others;

- Social persuasion, which refers to the ability of students to put more effort toward accomplishing a task because they were informed through persuasion that they are capable of doing such things;

- Physiological or mood state, which is about the judgment of an individual's mood to enhance or weaken his/her ability beliefs.

In fact, self-efficacy for self-regulated learning seems crucial for institutions of higher education. Thus, examining factors that may affect it helps in the development of the institutions and allows them to plan 
programs that could enhance students' self-efficacy, which will enhance their learning process (Van Dinther et al., 2011).

Within the Moroccan context, university students' performance and motivation toward learning have been an increasing problem. Motivation, for instance, is affected by other variables such as anxiety and students' efficacy beliefs. Thus, to enhance students' performance and motivation toward learning, it is important to examine their ability beliefs. It is also worth mentioning that there is a lack of research on university students' self-efficacy in the Moroccan context. For that reason, the main objectives of this study are to assess Moroccan university students' level of self-efficacy and compare the differences between their beliefs based on their institution, class level, gender, and professors' ability to motivate their students. In addition, this study aims to examine other factors, students' initial motives to join university and their living circumstances in particular, which may affect self-efficacy beliefs.

In general, this article investigated undergraduate students' self-efficacy beliefs and related factors in the context of Morocco, a country outside of Western European and American countries, which could promote the internationalization of the educational psychology field. In addition, the study yielded data that could potentially be informative and helpful with practical implications to improve students' self-efficacy and wellbeing. The following are the main research questions that this study sought to answer:

1. What is the level of Moroccan university students' self-efficacy beliefs and do these beliefs vary by institution, class level, professors' ability to motivate their students, and gender?

2. Do students' initial motives to enter a university and their living circumstances affect their academic self-efficacy?

\section{Self-Efficacy}

Self-efficacy was conceptualized by Bandura (1997) as "beliefs in one's capabilities to organize and execute the courses of action required to produce given attainments" (p. 3). The concept of self-efficacy gained popularity over the last two decades by being tackled in many studies (Stankov et al., 2014). Before introducing selfefficacy, Bandura talked about human motivation with a link to outcome expectations (Zimmerman, 2000). Later on, he distinguished between outcome and efficacy expectations. He interpreted efficacy expectations as being "the conviction that one can successfully execute the behavior required to produce the outcomes" (Bandura, 1977, p. 193). Additionally, Wang et al. (2013) discussed self-efficacy as an aspect of the selfregulation process. They also mentioned that within the self-regulation process, self-efficacy is often confused with self-confidence, self-concept, and self-esteem.

Several studies (e.g. Bong et al., 2012; Stankov et al., 2014; Zimmerman, 2000) differentiated between selfefficacy and self-concept because they are both confusing. For instance, Bong et al. (2012) linked self-efficacy to a person's capabilities, and self-concept to his/her feelings and being. More than that, they clarified that self-efficacy is developed through asking questions to check one's capabilities (in the form of 'can I?'). On the other hand, self-concept is developed through questions testing one's feelings (in the form of 'how do I feel?'). Consequently, they confirmed that answering self-efficacy questions resulted in the confidence in one's abilities to perform well while responding to self-concept questions revealed students' positive or negative judgments of themselves and their competencies. Additionally, Stankov et al. (2014) and Schunk (1991) confirmed that confidence is an accurate synonym of self-efficacy. This confidence or ability beliefs can be acquired and developed through many sources (Schunk, 2012).

\section{Sources of Self-Efficacy}

A study by Van Dinther et al. (2011) was conducted to illustrate and discover sources of self-efficacy beliefs and factors that affect these beliefs in higher education. They focused on reviewing the most recent studies that tackled this issue. Accordingly, goal-setting, rewards, modeling, task strategies, appraisal, feedback, and selfassessment or self-control were among the sources of efficacy beliefs that they reviewed, which can also affect students' self-efficacy in addition to Bandura's four main sources. Their findings confirmed the usefulness of Bandura's first three sources with some doubts about the second one (vicarious experience) because it relies on the conditions and the type of model used. Meanwhile, Bandura's first source (mastery experience) was found to be the strongest source that helps create a powerful sense of efficacy. 
In fact, the aim of the previous study was to investigate the intensity of Bandura's four sources of efficacy. However, the fourth source (physiological state) was only mentioned in the review and was not discussed while analyzing the findings. This could be because some physiological/mood states (e.g. stress and anxiety) might have more negative than positive effects on self-efficacy unless the individual had already built a higher sense of ability beliefs. Therefore, it can be concluded that their findings confirmed the validity of the first three sources as the most effective sources of efficacy. Additionally, they asserted that a combination of all the sources displayed favorable results as a powerful way of enhancing self-efficacy beliefs. However, the fourth source should not be ignored, especially since new research (e.g. Slimani et al., 2017) found that emotional and mood states can enhance communication and guarantee the quality of a task.

In spite of all the previous facts, it is necessary to point out that "self-efficacy is task specific and differs from context to context" (Raoofi et al., 2012, p. 61). Thus, all the previous sources of self-efficacy beliefs should be tackled based on the context. This means that self-efficacy differs according to the domain of functioning (Zajacova et al., 2005; Zimmerman, 2000). Due to that difference, self-efficacy beliefs should be measured according to specific contexts and settings (Gaffney, 2011). As reported by Zajacova et al. (2005), it is more beneficial to assess academic self-efficacy instead of general self-efficacy when dealing with education. They defined the term academic self-efficacy as "students' confidence in their ability to carry out such academic tasks as preparing for exams and writing term papers.” (p. 679).

More importantly, academic self-efficacy also includes competence and judgments about oneself to accomplish academic activities (MacPhee et al., 2013). In this specific setting, self-efficacy has been found to affect students' abilities (Gaffney, 2011). For instance, Chan and Lam (2008) conducted a study to investigate the impact of competition on learners' self-efficacy while using vicarious learning. The study involved 71 students who were appointed to either a competitive or a non-competitive classroom. The findings revealed that vicarious learning decreased students' sense of ability beliefs in a competitive classroom. On the other hand, students in the non-competitive classroom did not show any change. According to these results, it was suggested that students in the non-competitive classroom might not focus on outperforming others because of their mastery experience, which is known as the most effective source of self-efficacy.

\section{Self-Efficacy and Academic Achievement}

Research revealed that self-efficacy has a great effect on students' self-regulation, motivation, and outcomes (Schunk \& Pajares, 2009). Meanwhile, self-efficacy was found to be a powerful predictor of performance (Jinks \& Lorsbach, 2003). In a recent study, Weda et al. (2018) found a significant relationship between academic performance and self-efficacy beliefs. In the same way, Ngoc Truong and Wang (2019) found a positive correlation between self-efficacy and students' English performance. Additionally, a recent study by Sun and Wang (2020) confirmed that students' writing proficiency could be predicted through assessing their writing self-efficacy.

In fact, self-efficacy has a great effect on an individual's choice of settings and activities, persistence, and coping efforts (Bandura, 1977; Schunk, 1991). However, it was also found that self-efficacy alone cannot produce the desired outcome when the requested skills and knowledge are absent (Schunk, 1995). For instance, some cases require better skills, hard performance, and carry more risks than others (Bandura, 1977). In spite of this, self-efficacy beliefs are beneficial because they increase learners' competence and outcome expectations to achieve better results (Schunk, 1995). These facts lead us to a quote from the Roman poet Virgil "They are able who think they are able" (as cited in Pajares, 2002, p. 120).

In the same way, Mills et al. (2007) assured us in their study that teachers should cultivate and reinforce their students' self-efficacy beliefs since these beliefs were found to be related to academic success. Furthermore, their findings affirmed the significance of self-efficacy for self-regulation to achievement. The aim of their study was to check the influence of self-efficacy on the achievement of university students studying French (N = 303). Their findings demonstrated that female participants displayed higher self-efficacy for self-regulation than male participants. Meanwhile, this study confirmed that efficacious students employ strategies that are more convenient. 
Recently, Ngoc Truong and Wang (2019) conducted a study to examine self-efficacy beliefs of university students learning English as a foreign language $(\mathrm{N}=767)$. Their findings confirmed that mastery experience is a significant source of self-efficacy and that there is a positive relationship between English proficiency and self-efficacy beliefs. On the other hand, their results demonstrated no significant differences between females and males in terms of self-efficacy beliefs.

Within the Moroccan context, Benmansour (1999) investigated the motivational orientations and self-efficacy of 289 high school students learning mathematics. This study also confirmed that students' self-efficacy can be considered a predictor of their motivation and strategies use. Her findings demonstrated that high school students reported a moderate level of self-efficacy where the males' mean was higher than that of females. Moreover, this study confirmed that motivation is an important element in increasing students' beliefs in their abilities as discussed in several studies (e.g. Bartimote-Aufflick et al., 2016; Fenning \& May, 2013; Ghonsooly \& Golparvar, 2012; Karimzadeh, 2016; Omari et al., 2018; Zajacova et al., 2005; Zimmerman, 2000). In fact, selfefficacy is among the strongest motivational predictors of studying and outcome achievement (Mills et al., 2007). Accordingly, studying factors that may affect academic self-efficacy could enhance academic achievement.

\section{Factors Affecting Academic Self-efficacy}

Chan and Lam (2010) conducted two studies at the same time to examine the impact of four types of evaluation feedback on learners' self-efficacy beliefs. In the first study, they focused on providing students with formative or summative feedback. Formative feedback supplies students with strategic information that helps them correct their learning goal orientation and achieve the desired outcome; whereas the main point of summative feedback is to provide students with only the results of what they have done without giving them any information concerning goals achievement. In the second study, they provided students with norm-referenced feedback or self-referenced. The former focuses on giving students feedback on their performance or results in comparison with others. On the contrary, self-referenced feedback focuses on providing students with comments about their improvement in comparison with their previous achievement. The study revealed that both formative feedback and self-referenced feedback strengthen students' self-efficacy. On the contrary, summative feedback and norm-referenced feedback weaken students' self-efficacy. Thus, this research advised teachers to use formative and self-referenced evaluation as their feedback to enhance students' academic selfefficacy.

Other factors such as family, social, and cultural influences may affect students' academic self-efficacy beliefs. For instance, students' beliefs in their abilities can be affected by vicarious experiences (e.g. observing models like peers or parents) (Usher \& Pajares, 2008a). Schunk (1995) asserted that the type of support and encouragement provided by the parents could affect students' self-efficacy beliefs. He mentioned that parents and teachers could make a difference and enhance students' self-efficacy by motivating them to develop their skills, providing them with the needed learning resources, and by teaching them self-regulatory strategies.

Similarly, Schunk and Pajares (2009) pointed out that educated parents positively influence students' learning processes and help them develop and foster their self-efficacy beliefs. Meanwhile, Fan and Williams (2010) conducted a study to examine whether parents' involvement in their children's education predicted their selfefficacy or not. The findings showed that parents' involvement affected students' self-efficacy toward English. As they reported, the involvement of parents increases the students' sense of competence. In fact, the parents' role in enhancing the students' sense of efficacy can be achieved through making them aware that "academic success is a matter of desire, effort, and commitment" (Pajares, 2002, p. 123). Meanwhile, it should also be noted that past research has confirmed a reciprocal effect between self-efficacy and interest (Cordova et al., 2014; Lent et al., 2006; Silvia, 2003; Tracey, 2002; Tracey \& Hopkins, 2001). In general, parents' and teachers' efforts to enhance students' self-efficacy beliefs can provide good results whatever the living circumstances of the learners.

In Morocco, most university students live with their parents or family during the academic year unless the university is located elsewhere. For that reason, students' living circumstances could vary from, for instance, living alone, living with parents, or living with a friend/classmate in a shared room or apartment. In fact, more research is required about the impact of these circumstances on university students' self-efficacy. A recent unique study by Koçak and Canli (2019) investigated the self-efficacy beliefs of 386 university students studying 
sports according to the place they were raised. Their findings demonstrated that participants who were raised in a province or district reported higher self-efficacy beliefs than those who were raised in a village. On the other hand, no significant differences were found among students' self-efficacy levels with regard to gender, age, and class level.

Concerning self-efficacy and gender, several studies found that differences between males' and females' selfefficacy were not significant (Azar, 2010; Clutts, 2010; Vuong et al., 2010; Yoestara \& Putri, 2019). However, the findings of Vogt et al. (2007) and Altunsoy et al. (2010) demonstrated that the differences in the scores between males and females were significant in favor of males. On the other hand, significant differences in favor of female participants were found in other studies (e.g. MacPhee et al., 2013; Mahyuddin et al., 2006; Mills et al., 2007). In terms of class level and self-efficacy, some studies (e.g. Ağgül Yalçin, 2011; Altunsoy et al., 2010) confirmed that the differences between class levels were significant. Their findings also confirmed that students' ability beliefs increase as their class level increases.

\section{Methodology}

\section{Participants}

The current study involved 365 undergraduate university students from multiple regions in Morocco. A quantitative method was used where data were collected using pen and paper questionnaires. It is worth noting that these questionnaires were completed anonymously by the participants. The data collection was carried out in the middle of the second semester in three universities in Morocco: Moulay Ismail University (MIU) in Meknes, Sidi Mohamed Ben Abdellah University (SMBAU) Dhar El Mehraz in Fez, and Al Akhawayn University (AUI) in Ifrane. The latter is a private institution of higher education; however, both MIU and SMBAU are public institutions of higher education. These universities enroll students from different social classes. Students from MIU and SMBAU do not pay fees, as these universities are open access and do not require an entrance exam. On the contrary, students from AUI pay fees and they are required to take an entrance exam.

This study was conducted in English using a nonrandom sampling method. Meanwhile, the target population was undergraduate university students and the participants were selected for reasons of convenience and accessibility. For that reason, undergraduate students from the departments of English at the Faculty of Letters and Humanities in both MIU $(n=116)$ and SMBAU $(n=139)$ participated in that study. This was not the case for AUI students $(\mathrm{n}=110)$ as there is no department of English at that university and English is the main medium of instruction. AUI participants were from the Department of Communication Studies as the latter is more compatible to the department of English in public universities.

Altogether, 400 questionnaires were distributed, of which 365 were completed, 14 were incomplete (6 from MIU, 5 from SMBAU, 3 from AUI), 11 were rejected due to honesty matters (5 from MIU, 4 from SMBAU, 2 from AUI), and 10 were not returned ( 6 from MIU, and 4 from SMBAU). With regard to gender, about $58 \%$ of the students who participated in this study were females whereas only $42 \%$ were males. Females were represented more than males because many male participants did not agree to participate. In addition, participants were from different levels as follows: 121 from the first year (33.20\%), 118 from the second year (32.30\%), and 126 from the third year (34.50\%).

\section{Instrument, Procedure, and Materials}

In the current study, an educational psychology instrument was used to examine participants' self-efficacy. Demographic information was also employed to collect demographic data. University students' self-efficacy was evaluated through a students' self-efficacy scale. This scale measured participants' self-efficacy within the category of self-efficacy for self-regulated learning. In general, the administered questionnaire was composed of two main sections. The first section involved demographic information questions whereas the second one involved the self-efficacy scale. 


\section{Demographic information}

A set of questions were included in the demographic information section to collect participants' gender, class level, and university. In addition, this section comprised a multiple-choice question about students' living circumstances during the academic year (Where do you live during the academic year? alone, with parents, in a shared room/apartment). Other specific questions were also involved in the first part of the questionnaire. These questions were used to examine participants' motive behind enrolling in university (Multiple response question: Why did you decide to go to university?), and whether they felt that their professors motivated them or not (Do you feel that any of your professors are motivating you to do your best and work hard?).

\section{Students' Self-Efficacy Scale}

The students' self-efficacy scale in this study was adapted from Zimmerman et al. (1992). In fact, the authors provided two scales of self-efficacy in their study. The first one measured students' self-efficacy for selfregulated learning (11 items); whereas the second one measured their self-efficacy for academic achievement ( 9 items). Researchers found that items that were designed to assess self-regulated learning efficacy (first scale) were mostly associated with academic self-efficacy (Choi et al., 2001). Thus, the first scale from Zimmerman et al. (1992) was the one used in this study. A pilot study was then used to test the adapted scale (11 items) and the demographic information form. This was carried out to test whether the questionnaire was appropriate and comprehensible, and that the items were clearly understood and consistent. The first version of the questionnaire was distributed to 30 undergraduate English majors at the University of Sidi Mohamed Ben Abdellah in Fez. Participants in this pilot study were asked whether they experienced any obstacles or difficulties while filling in the questionnaire. Their remarks and feedback were taken into account while making up the questionnaire's final version.

Ten items assessing participants' ability to employ and practice different self-regulated learning strategies were included in the scale's final version (See Appendix). Sample items that assessed students' "self-efficacy for self-regulated learning" included "Indicate how well you can finish homework assignments by the deadlines, how well you can take class notes, and how well you can participate in class discussions". The concept 'internet' was added to the fifth item upon listening to the remarks of students in the pilot study and since it is now widely used to get access to online books and information. Thus, the fifth item was changed to "Indicate how well you can use the library/internet to get information for class assignments". In addition, two items from the same scale were gathered to form only one item. This was the case for the sixth item, "Indicate how well you can plan and organize your classwork".

In general, the whole scale was revised and some terms were modified to be relevant for higher education (e.g. schoolwork changed to classwork - school subjects changed to class subjects). Students reacted to the scale of self-efficacy on a 5-point Likert-type scale from (1) "not well at all" to (5) "very well" with a midpoint at (3) "somewhat".

\section{Data Analysis}

The Statistical Package for Social Sciences (SPSS) version 24 was used to code and analyze the data. In terms of the scale's reliability, Zimmerman et al. (1992) performed a Cronbach's alpha reliability tests and achieved a coefficient of .87. Meanwhile, Zimmerman \& Martinez-Pons (1988) proved in a validation study that one factor underlay the items. Across studies, different Cronbach's alpha coefficients ranging from .78 to .87 have been reported by researchers (Britner \& Pajares, 2006; Pajares, 1996; Pajares \& Graham, 1999; Usher \& Pajares, 2006, 2008b).

A reliability analysis was performed to measure the reliability of the current scale. The Cronbach's alpha coefficient of .83 was found for the scale of self-efficacy in this study. Moreover, the "Cronbach's Alpha if item deleted" test demonstrated that all of the scale items were reliable and that the alpha $(\alpha)$ value would decrease if any of the items were deleted. Therefore, this result confirmed the scale's reliability and validity in the current study. 
Concerning data analysis, descriptive statistics including means (M) and standard deviations (SD) were performed on every variable. In addition, one-way ANOVA tests and a set of $t$-tests were carried out to discover whether the variances between variables were statistically significant or not.

Overall, a nonrandom sampling technique was employed as a procedure in this study. Additionally, the clarity of the questionnaire was tested via a pilot study. During this stage, remarks and observations were gathered and taken into consideration while making up the final version of the questionnaire. After that, pen and paper questionnaires were distributed and anonymously completed by the participants.

\section{Results}

\section{Descriptive Results}

\section{Research Question One}

What is the level of Moroccan university students' self-efficacy beliefs and do these beliefs vary by institution, class level, professors' ability to motivate their students, and gender? To answer this research question, several tests were conducted to examine inter-group variances in terms of self-efficacy for self-regulated learning.

Students in this study reported a moderate level of self-efficacy for self-regulated learning with a mean of $(\mathrm{M}=$ $3.56, \mathrm{SD}=1.02)$. In general, students within each university did not show a high difference in their self-efficacy total score. For instance, the highest mean of self-efficacy was that of students from AUI $(M=3.67, \mathrm{SD}=0.98)$. However, the scores of the self-efficacy scale for MIU and SMBAU students were very close, $(M=3.53, \mathrm{SD}=1.03)$ and $(M=3.50, \mathrm{SD}=1.05)$ respectively.

Related to that, a one way ANOVA test was carried out (see Table 1) to discover whether the variances between the institutions in terms of self-efficacy were significant or not. The results showed that there was a statistically significant difference between the scores for the three institutions at the $\mathrm{p}<.05$ level $[\mathrm{F}(2,362)=5.10, \mathrm{p}=0.007]$. Meanwhile, post hoc comparisons using the TUKEY HSD test showed that the self-efficacy mean for AUI students $(\mathrm{M}=3.67, \mathrm{SD}=0.98)$ was statistically different from that of $\mathrm{MIU}(\mathrm{M}=3.53, \mathrm{SD}=1.03)$ and SMBAU $(\mathrm{M}=$ $3.50, \mathrm{SD}=1.05)$ students. However, the mean of students from MIU did not statistically differ from that of SMBAU students and vice versa. Taken together, these results suggest that the self-efficacy of AUI participants was significantly different and higher than that of students from MIU and SMBAU.

Table 1

ANOVA test for institution and self-efficacy

\begin{tabular}{lccccc}
\hline & Sum of Squares & Df & Mean Square & F & Sig. \\
\hline Between Groups & 2.744 & 2 & 1.372 & 5.102 & .007 \\
Within Groups & 97.335 & 362 & 0.269 & & \\
Total & 100.079 & 364 & & & \\
\hline
\end{tabular}

In terms of the highest and lowest items, "being able to take class notes" $(M=3.89, \mathrm{SD}=1.01)$ was the highest rated item and "being able to study when there are other interesting things to do" $(M=3.01, \mathrm{SD}=1.01)$ was the lowest. Regarding the detailed scores of self-efficacy items within each university, means ranged from $(M=$ 2.94 ), which falls between not too well and somewhat, for item 10 "I can participate in class discussions" to ( $M=$ 4.04), which falls within pretty well, for item 4 "I can take class notes". Both means of item 4 (highest) and item 10 (lowest) were scored by MIU students. Meanwhile, the majority of the highest means for most items were scored by AUI students. For instance, AUI students rated their abilities to "finish homework assignments by the deadlines" $(M=3.96)$ and their "ability to participate in classroom discussions" $(M=3.94)$ higher than MIU students (respectively, $\mathrm{M}=3.35, \mathrm{M}=2.94)$ and SMBAU students $(\mathrm{M}=3.33, \mathrm{M}=3.19$ ).

On the other hand, students of SMBAU rated their "abilities to plan and organize their classwork" as the highest $(M=3.41)$ compared with students of MIU $(\mathrm{M}=3.37)$ and AUI $(\mathrm{M}=3.34)$. However, their abilities to "finish 
homework assignments by the deadlines" $(M=3.33)$ and to "arrange a place where they can study without distraction" $(M=3.27)$ were the lowest compared with participants from the other universities. Additionally, students of MIU rated their abilities to "study when there are other interesting things to do" as the lowest $(M=2.95)$ in comparison with the others. Details of self-efficacy means and standard deviation of items within each university could be found in the Appendix.

Regarding class level, third-year university students' self-efficacy for self-regulated learning mean score across all three universities was higher $(M=3.69)$ than the mean score of second-year $(M=3.53)$ and first-year $(M=$ 3.46) students. The mean of self-efficacy for third-year students at MIU was 3.76; however, the means were somewhat similar for second and first-year students (respectively $M=3.50 ; M=3.51$ ). Within SMBAU, the mean of self-efficacy for third-year students was 3.59; and it was 3.36 for second-year and 3.41 for first-year students. Concerning participants from AUI, the lowest mean of self-efficacy was that of first-year students $(M$ = 3.50). Meanwhile, second-year students from AUI scored higher than first-year students $(M=3.64)$. On the other hand, third-year students' mean was the highest within AUI and within the other universities $(M=3.79)$.

Within the same variable, a one way ANOVA was performed to compare the class level effect on students' selfefficacy for self-regulated learning. The findings demonstrated that there was a statistically significant effect for class level on students' self-efficacy for the three class levels at the $\mathrm{p}<.05$ level [F $(2,362=5.78, \mathrm{p}=.003]$. Post hoc comparisons indicated that third-year students' self-efficacy $(\mathrm{M}=3.69)$ was significantly different from that of first-year $(\mathrm{M}=3.46)$ and second-year students $(\mathrm{M}=3.53)$. On the contrary, the mean of secondyear students did not significantly differ from the mean of first-year students. This means that the self-efficacy of third-year students is statistically different and higher than that of both first and second-year students.

In terms of professors' ability to motivate their students and self-efficacy, all of the students who reported that their professors motivated them within the three universities displayed higher self-efficacy and their mean scores were higher $(M=3.69)$ than those who stated the opposite $(M=3.42)$. The highest mean was that of AUI students, who indicated that their professors motivated them $(M=3.79)$ as demonstrated in Table 2.

To discover whether there were significant differences between the self-efficacy scores of students who reported that their professors motivated them (group 1) and those who said the opposite (group 2), an independent samples t-test was carried out. The test indicated that the difference in the scores between the first group $(M=$ $3.69)$ and the second one $(M=3.42)$ was significant, $\mathrm{t}(362)=2.74, \mathrm{p}=.007$.

Table 2

Means of self-efficacy based on whether students feel that their professors motivated them or not

\begin{tabular}{|c|c|c|c|}
\hline & & SE Mean & $\mathbf{N}$ \\
\hline \multirow{3}{*}{ MIU } & Yes & 3.64 & 81 \\
\hline & No & 3.39 & 35 \\
\hline & Total & 3.53 & 116 \\
\hline \multirow{3}{*}{ SMBAU } & Yes & 3.60 & 103 \\
\hline & No & 3.37 & 35 \\
\hline & Total & 3.50 & 138 \\
\hline \multirow{3}{*}{ AUI } & Yes & 3.79 & 82 \\
\hline & No & 3.54 & 28 \\
\hline & Total & 3.67 & 110 \\
\hline \multirow{3}{*}{ Total } & Yes & 3.69 & 266 \\
\hline & No & 3.42 & 98 \\
\hline & Total & 3.56 & 364 \\
\hline
\end{tabular}

Note. Yes $=$ my professor motivates me to work hard. No $=$ my professor does not motivate me.

With regard to self-efficacy and gender, the females' mean for self-efficacy was $(M=3.59)$ and the males' mean was $(M=3.51)$. Meanwhile, females within MIU scored a mean of 3.64, which falls near to the 'pretty-well' level to self-regulate their learning. Males within the same university scored lower on the self-efficacy scale $(M=$ 3.42). Similarly, the mean of self-efficacy for females within SMBAU $(M=3.51)$ was higher than the mean of 
males $(M=3.43)$. On the contrary, the self-efficacy mean of males within AUI $(M=3.69)$ was a little bit higher than that of the females $(M=3.63)$.

An independent samples t-test was performed to compare the means of self-efficacy between male and female participants. The findings demonstrated that the difference in the means between males $(M=3.51)$ and females $(M=3.59)$ was not significant, $\mathrm{t}(363)=-0.24, \mathrm{p}=.81$. Thus, this confirms that the difference between the two groups (males and females) in terms of self-efficacy is not statistically significant and that the differences between the means were likely due to chance.

\section{Research question two}

Do students' initial motives to enter a university and their living circumstances affect their academic selfefficacy? To answer this research question, several tests were performed.

A one way ANOVA was conducted to find out if there was a significant effect from students' living circumstances during the academic year on self-efficacy. The results showed that the effect of students' living circumstances on their self-efficacy was statistically significant at the $\mathrm{p}<.05$ level $[\mathrm{F}(2,359=6.55, \mathrm{p}=.002]$. Post hoc comparisons indicated that the self-efficacy of students who reported that they live alone $(\mathrm{M}=3.75, \mathrm{SD}=1.01)$ was statistically different from the ones who said that they live with their parents $(M=3.47, S D=1.07$ ) (see Table 3 below). On the contrary, the mean of students who reported that they live in a shared room/apartment $(\mathrm{M}=3.57, \mathrm{SD}=0.97)$ did not significantly differ from that of the other mentioned groups. It is also worth mentioning that students who live alone in the three institutions demonstrated higher levels of self-efficacy (AUI, $\mathrm{M}=3.86$; SMBAU, $\mathrm{M}=3.76$; $\mathrm{MIU}, \mathrm{M}=3.60$ ) than the ones who live in a shared room/apartment (AUI, $\mathrm{M}=$ 3.50; SMBAU, $\mathrm{M}=3.75$; $\mathrm{MIU}, \mathrm{M}=3.47$ ) or with their parents (AUI, $\mathrm{M}=3.31$; SMBAU, $\mathrm{M}=3.56$; $\mathrm{MIU}, \mathrm{M}=3.54$ ) as demonstrated in Table 3 below.

Table 3

Means of self-efficacy based on participants' living circumstances and university

\begin{tabular}{lccc}
\hline \multicolumn{1}{c}{ Students' living circumstances during the academic year } & University & SE Mean & N \\
\hline & MIU & 3.60 & 31 \\
Alone & SMBAU & 3.76 & 22 \\
& AUI & 3.86 & 49 \\
& Total & 3.75 & 102 \\
With parents & MIU & 3.54 & 56 \\
& SMBAU & 3.56 & 95 \\
& AUI & 3.31 & 16 \\
Shared room/apartment & Total & 3.47 & 167 \\
& MIU & 3.47 & 27 \\
& SMBAU & 3.75 & 22 \\
\end{tabular}

The participants pointed out that the most common reasons why they joined their university involved either an interest in their subject of study or their desire to achieve a higher degree, as shown in Table 4 below. It is worth noting here that this item was a multiple response question (select all that apply). The responses were selected based on the answers and feedback of the participants in the pilot study. The participants were allowed to select more than one reason why they joined their university. Concerning students' mean scores of selfefficacy according to their initial motive behind joining their university, the mean score of those who mentioned that they enrolled in university to achieve a higher degree was the highest $(M=3.76)$ compared with that of those who were interested in their subject $(M=3.69)$, advised by a teacher or a family member $(M=3.54)$, and the ones who joined university because it was their only possible option $(M=3.24)$.

More specifically, the lowest score was that of participants from MIU who declared that they joined their university because it was the only possible option $(M=3.20)$. The other highest means were $M=3.84$ for AUI students and $\mathrm{M}=3.78$ for SMBAU students who mentioned that their decision was because of their desire to 
get a higher degree. This was followed by a mean of $\mathrm{M}=3.67$ for MIU students who decided to go to university because they were advised by a family member or a teacher, a mean of $\mathrm{M}=3.71$ for AUI students, and $\mathrm{M}=3.68$ for MIU students who stated that they were interested in their subject.

Table 4

Means of self-efficacy based on participants' initial motive behind joining university

\begin{tabular}{|c|c|c|c|c|c|}
\hline & & \multirow[t]{2}{*}{$\mathbf{N}$} & \multirow[t]{2}{*}{ Responses \% } & \multicolumn{2}{|c|}{ Mean of Self-efficacy } \\
\hline & & & & Checked & Unchecked \\
\hline \multirow{6}{*}{ Why did you decide to go to university? ${ }^{a}$} & Interested in their subject & 173 & $41.1 \%$ & 3.69 & 3.55 \\
\hline & Advised by a teacher/family member & 24 & $5.7 \%$ & 3.54 & 3.57 \\
\hline & To achieve a higher degree & 157 & $37.3 \%$ & 3.76 & 3.46 \\
\hline & The only choice & 57 & $13.5 \%$ & 3.24 & 3.65 \\
\hline & None of the above & 10 & $2.4 \%$ & 3.49 & 3.57 \\
\hline & Total & 421 & $100 \%$ & & \\
\hline
\end{tabular}

Note. $\mathrm{N}$ total is based on responses.

a Dichotomy group tabulated at value 1 .

Several independent samples t-tests were performed to discover whether the differences between students' means of self-efficacy with regard to their initial motive to join university were significant or not. The tests displayed that the differences in the scores were significant between participants who checked that they decided to join university because of an interest in their subject $(\mathrm{M}=3.69)[\mathrm{t}(363)=4.34, \mathrm{p}=.006]$, desire to achieve a higher degree $(\mathrm{M}=3.76)[\mathrm{t}(363)=4.74, \mathrm{p}=.001]$, it was their only choice $(\mathrm{M}=3.24)[\mathrm{t}(363)=-5.23, \mathrm{p}$ $=.001]$, and those who did not check any of the mentioned reasons (respectively, $\mathrm{M}=3.55 ; \mathrm{M}=3.46 ; \mathrm{M}=3.65$ ). These results suggest that students' interest in their subject of study and their willingness to get a higher degree really do have a positive impact on their self-efficacy. Moreover, studying at university because it is one's only choice shows that it has a negative impact on students' self-efficacy. Specifically, our results show that when students go to university because it is their only choice, their self-efficacy for self-regulated learning decreases.

\section{Summary of Findings}

\section{Discussion}

The participants in this study reported a moderate level of ability beliefs. Meanwhile, students from AUI showed somewhat higher self-efficacy beliefs than participants from the other universities, although there was not a big difference between the scores. Participants from MIU and SMBAU reported the same degree of self-efficacy. Within self-efficacy items, the results indicated that students' ability beliefs to take class notes were the highest. On the other hand, their beliefs to study in the presence of other entertaining activities were the lowest. Moreover, self-efficacy beliefs to participate in class discussions and to finish homework assignments by the deadlines of participants from MIU and SMBAU were moderate. On the contrary, AUI students displayed higher-ability beliefs to finish homework assignments by the deadlines and also participate in class discussions than participants from the other universities.

In terms of self-efficacy within class levels, the findings demonstrated that all third-year undergraduate students were more efficacious than first and second-year students. Similarly, students who live alone during the academic year were found more efficacious than those who live in a shared room/apartment or with their parents. The results also revealed that participants who joined their university because it was their only possible option were less efficacious than those who were interested in their subject or wanted to achieve a higher degree. Students within the two latter cases displayed more ability beliefs to self-regulate their learning. In the same way, all of the participants who said that their professors motivated them to work hard and do their best were found more efficacious than those who said the opposite. 


\section{Research Question One}

The findings revealed that the participants possessed a moderate level of self-efficacy for self-regulated learning $(M=3.56)$. This is consistent with the findings of Benmansour (1999). The results also demonstrated that there was a tenuous difference between learners' self-efficacy within the three universities. The achieved results of students' self-efficacy for self-regulated learning may explain the common complaints of some professors and practitioners in higher education toward students' low performance. As confirmed by the results, students' low performance could be due to the moderate beliefs in their abilities. Previous studies (e.g. Ngoc Truong \& Wang, 2019; Weda et al., 2018; Zajacova et al., 2005) found a significant correlation between academic performance and self-efficacy beliefs. Meanwhile, students from AUI displayed a slight difference in terms of self-efficacy, but it was less than what was expected since AUI is a private institution and it offers more facilities to its students. This means that learners' beliefs in their abilities are not an issue of being enrolled in a private or a public university. According to Van Dinther et al. (2011), the most important thing is to offer students a classroom where they can study within a safe environment. Therefore, it is all about students' beliefs that they can do certain activities within certain circumstances.

In the same way, the participants within the three universities did not display a high difference in their selfefficacy with regard to class level. However, all third-year students were found more efficacious than first and second-year students. This could be because third-year students have developed more strategies in terms of self-regulation. More than that, this difference between third-year students and the others could be due to their mastery experience. The latter was classified by Bandura (2010) as the most effective source of selfefficacy beliefs. Thus, the results of the current study support this fact. Each year students acquire new things and develop strategies that in return affect their belief in their abilities. These findings support previous claims that students develop self-efficacy beliefs as they advance (e.g. Ağgül Yalçin, 2011; Altunsoy et al., 2010; Meece et al., 2006).

The findings also demonstrated that all of the participants who declared that their professors motivated them to work hard were more efficacious than those who indicated the opposite. These results suggest that motivating students really does have an effect on students' self-efficacy. Specifically, our results show that when students are motivated by their teachers, their self-efficacy for self-regulated learning increases. This finding confirms Schunk's (1995) assertion that teachers could make a difference and enhance students' selfefficacy by motivating them to develop their skills, providing them with the needed learning resources, and teaching them self-regulatory strategies.

Additionally, it is worth mentioning that a link was found between students' beliefs about whether their professors motivated them or not and their initial motive behind joining their university. For instance, students in this study who joined university due to the fact that it was their only possible option were found more likely to declare that their professors did not motivate them. It is also important to mention that other participants from the same class revealed that their professors motivated them. This is to say that the reason behind students' enrollment in a university could have an effect on their overall motivation as confirmed by Omari et al. (2018).

Concerning gender, the results of this study demonstrated that no statistically significant differences were found between males' and females' self-efficacy and that the differences between the means were likely due to chance. This is consistent with the findings of Ngoc Truong and Wang (2019) and other studies (Azar, 2010; Clutts, 2010; Koçak \& Canli, 2019; Vuong et al., 2010; Yoestara \& Putri, 2019). However, although the differences between males' and females' self-efficacy beliefs were significant in favor of males in some studies (e.g. Altunsoy et al., 2010; Vogt et al., 2007), other studies (e.g. MacPhee et al., 2013; Mahyuddin et al., 2006; Mills et al., 2007) indicated that females usually report greater ability beliefs than males. Meanwhile, Mills et al. (2007) pointed out that this disparity between self-efficacy beliefs of males and females is because female students tend to designate more time to course work. In fact, some students may feel lazy toward course work. Most of the time, laziness makes students unwilling to do class work or participate in voluntary work. Accordingly, this can explain why some participants (mostly females) agreed to participate in this study more than others (mostly males). 


\section{Research Question Two}

Other findings in this study demonstrated that participants who do not live with their parents over the academic year reported higher efficacy beliefs than those who live with their parents. Taking into consideration the findings of some studies that parents' support affects students' self-efficacy (e.g. Fan \& Williams, 2010; Schunk, 1995), we can conclude that students who are away from their parents probably receive more verbal and financial support than those who live with their parents. This may be also due to the fact that learners who live away from their parents appreciate and value their parents' financial and emotional support. Thus, they try to develop learning strategies to give something in return to their parents (such as learning achievements). It is also worth noting that most students in Morocco depend on the financial support of their parents/family to complete their undergraduate studies. For that reason, students who live alone may receive encouragement from their parents/family and this could play a crucial role in making their beliefs higher as research has confirmed the significance of social persuasion as a source of self-efficacy (Bandura, 2010). Parents' education also plays a crucial role as a variable that improves students' self-efficacy. Previous studies have confirmed that educated parents help with enhancing students’ self-efficacy (Schunk \& Pajares, 2009).

The results of this study showed that students who decided to join their university due to an interest in their subject or to obtain a degree were more efficacious than those who enrolled in their university because it was their only choice. Thus, it can be concluded that initial motives affect students' beliefs in their abilities. In other words, students who accept that going to university is their only choice may not have strong beliefs in their abilities. In the same way, they may consider themselves unable to perform such tasks because they lack interest. Hence, they will report a degree of self-efficacy according to their initial reasons behind joining the university. Similar findings were achieved in a previous study by Omari et al. (2018) concerning students' motivation. The findings of this study support their results because motivation and self-efficacy are interrelated. These results are also compatible with other studies that confirmed the reciprocal effect between self-efficacy and interest (Cordova et al., 2014; Lent et al., 2006; Silvia, 2003; Tracey, 2002; Tracey \& Hopkins, 2001). Overall, our results confirm that when students go to university because it is their only choice, their self-efficacy for self-regulated learning decreases.

\section{Implications and Limitations}

In this study, self-efficacy provides information that can help professors and researchers draw an idea in their minds concerning students' beliefs in their abilities. Those beliefs according to Zimmerman et al. (1992) are considered determinants of students' aspirations. The findings of this study have implications on students' regulation and behavior toward learning. An efficacious student puts in more efforts and does not give up easily while performing a difficult task. Moreover, the findings of the current study indicate that giving more importance to self-efficacy for self-regulated learning helps learners perform better. For that reason, university professors should encourage their students to talk about their self-efficacy beliefs, for instance while performing a task to enhance their learning. Including self-efficacy scales in articles or handouts could be also of great benefit. Meanwhile, university professors should consider the variables and elements that affect the self-efficacy of students, especially the ones that weaken learners' self-efficacy beliefs. The findings of this study could facilitate and clarify the techniques that should be used to strengthen students' beliefs, which will positively affect their performance. In general, the findings alongside with the framework presented in the literature might play a crucial part in the improvement of Moroccan universities.

On the other hand, the results of the current study could be restricted to a population similar to students at an undergraduate level from Sidi Mohamed Ben Abdellah University, Moulay Ismail University, and Al Akhawayn University. In addition, the current study was limited to participants from the department of English at SMBAU and MIU, and other students who master English (AUI). This was with the purpose of examining participants' self-efficacy for self-regulated learning. Meanwhile, the collected data were limited to 365 participants because of the encountered difficulties while convincing others to take part in the study. Hence, the generalization of the findings might be only to learners from the same mentioned universities.

Overall, more research in different Moroccan universities is necessary to evaluate self-efficacy for self-regulated learning in the Moroccan context. Future researchers should focus on sampling from specific contexts. Additional research is also required concerning the impact of teachers' feedback on learners' academic 
achievement and self-efficacy, especially within higher education. Moreover, further research is also needed regarding the differences between students who live alone and those who live with their parents in terms of their self-efficacy beliefs and reasons for these differences, if applicable.

\section{Conclusion}

In general, the results of this study indicate the importance of self-efficacy beliefs to enhance students' learning performance. This study shows that students' living circumstances during the academic year, their level of education, their point of view on whether any of their professors motivated them, and their initial motive behind enrolling in university could be considered as predictors of self-efficacy. Moreover, this study demonstrates that learners who live far away from their parents during the academic year could be more efficacious than others who live with their parents. Meanwhile, first-year students may have fewer beliefs in their abilities than third-year students. Similarly, the ability of professors to motivate their students as well as joining a university for a good reason or a goal could increase one's self-efficacy beliefs. More importantly, the small difference between universities with regard to self-efficacy for self-regulated learning confirms that studying in a public or a private institution does not matter. In fact, what matters most in learning is the ability to provide a classroom where students can study in a safe environment. Again, this proves Virgil's quote that "They are able who think they are able" (as cited in Pajares, 2002, p. 120).

\section{Conflict of Interest}

The authors declare that they have no conflict of interest.

\section{References}

Ağgül Yalçin, F. (2011). Investigation of science teacher candidates' self-efficacy beliefs of science teaching with respect to some variables. International Online Journal of Educational Sciences, 3(3), 1046-1063. https://doi. org/10.18844/gihss.v3i1.1774

Altunsoy, S., Çimen, O., Ekici, G., Atik, A. D., \& Gökmen, A. (2010). An assessment of the factors that influence biology teacher candidates' levels of academic self-efficacy. Procedia - Social and Behavioral Sciences, 2(2), 2377-2382. https://doi.org/10.1016/j.sbspro.2010.03.340

Azar, A. (2010). In-service and pre-service secondary science teachers' self-efficacy beliefs about science teaching. Educational Research and Reviews, 5(4), 175-188. https://doi.org/10.5897/ERR09.243

Bandura, A. (1977). Self-efficacy: Toward a unifying theory of behavioral change. Psychological Review, 84(2), 191-215. https://doi.org/10.1037/0033-295X.84.2.191

Bandura, A. (1997). Self-efficacy: The exercise of control. W.H. Freeman and Company.

Bandura, A. (2010). Self-efficacy. In The corsini encyclopedia of psychology. John Wiley \& Sons, Inc. https://doi. org/10.1002/9780470479216.corpsy0836

Bartimote-Aufflick, K., Bridgeman, A., Walker, R., Sharma, M., \& Smith, L. (2016). The study, evaluation, and improvement of university student self-efficacy. Studies in Higher Education, 41(11), 1918-1942. https://doi. org/10.1080/03075079.2014.999319

Benmansour, N. (1999). Motivational orientations, self-efficacy, anxiety and strategy use in learning high school mathematics in Morocco. Mediterranean Journal of Educational Studies, 4(1), 1-15.

Bong, M., Cho, C., Ahn, H. S., \& Kim, H. J. (2012). Comparison of self-beliefs for predicting student motivation and achievement. The Journal of Educational Research, 105(5), 336-352. https://doi.org/10.1080/00220671.2 011.627401

Britner, S. L., \& Pajares, F. (2006). Sources of science self-efficacy beliefs of middle school students. Journal of Research in Science Teaching, 43(5), 485-499. https://doi.org/10.1002/tea.20131

Chan, J. C. Y., \& Lam, S. F. (2008). Effects of competition on students' self-efficacy in vicarious learning. British Journal of Educational Psychology, 78(1), 95-108. https://doi.org/10.1348/000709907X185509 
Chan, J. C. Y., \& Lam, S. fong. (2010). Effects of different evaluative feedback on students' self-efficacy in learning. Instructional Science, 38(1), 37-58. https://doi.org/10.1007/s11251-008-9077-2

Choi, N., Fuqua, D. R., \& Griffin, B. W. (2001). Exploratory analysis of the structure of scores from the multidimensional scales of perceived self-efficacy. Educational and Psychological Measurement, 61(3), 475489. https://doi.org/10.1177/00131640121971338

Clutts, D. W. (2010). Mathematics self-efficacy of community college students in developmental mathematics courses. Liberty University.

Cordova, J. R., Sinatra, G. M., Jones, S. H., Taasoobshirazi, G., \& Lombardi, D. (2014). Confidence in prior knowledge, self-efficacy, interest and prior knowledge: Influences on conceptual change. Contemporary Educational Psychology, 39(2), 164-174. https://doi.org/https://doi.org/10.1016/j.cedpsych.2014.03.006

Fan, W., \& Williams, C. M. (2010). The effects of parental involvement on students' academic selfefficacy, engagement and intrinsic motivation. Educational Psychology, 30(1), 53-74. https://doi. org/10.1080/01443410903353302

Fenning, B., \& May, L. (2013). "Where there is a will, there is an A": Examining the roles of self-efficacy and self-concept in college students' current educational attainment and career planning. Social Psychology of Education, 16(4), 635-650. https://doi.org/10.1007/s11218-013-9228-4

Gaffney, A. L. H. (2011). Measuring students' self-efficacy for communication. International Journal of Art \& Design Education, 30(2), 211-225. https://doi.org/10.1111/j.1476-8070.2011.01702.x

Ghonsooly, B., \& Golparvar, S.E. (2012). General English university students' self-efficacy and their achievement. Iranian EFL Journal, 8(3), 153-173.

Jinks, J., \& Lorsbach, A. (2003). Introduction: motivation and self-eefficacy belief. Reading \& Writing Quarterly, 19(2), 113-118. https://doi.org/10.1080/10573560308218

Karimzadeh, K. (2016). Do self-regulation, self-efficacy, and motivation predict listening comprehension? The Iranian EFL Journal, 12(2), 99-119.

Koçak, Ç. V., \& Canli, U. (2019). Investigation of academic self efficacy of university students in the sports area. Asian Journal of Education and Training, 5(1), 56-62. https://doi.org/10.20448/journal.522.2019.51.56.62

Lent, R. W., Tracey, T. J. G., Brown, S. D., Soresi, S., \& Nota, L. (2006). Development of interests and competency beliefs in Italian adolescents: An exploration of circumplex structure and bidirectional relationships. Journal of Counseling Psychology, 53(2), 181-191. https://doi.org/https://doi.org/10.1037/0022-0167.53.2.181

MacPhee, D., Farro, S., \& Canetto, S. S. (2013). Academic self-efficacy and performance of underrepresented stem majors: Gender, ethnic, and social class patterns. Analyses of Social Issues and Public Policy, 13(1), 347369. https://doi.org/10.1111/asap.12033

Mahyuddin, R., Elias, H., Cheong, L. S., Muhamad, M. F., Noordin, N., \& Abdullah, M. C. (2006). The relationship between students' self efficacy and their English language achievement. Malaysian Journal of Educators and Education, 21, 61-71.

Matthews, P. H. (2010). Factors influencing self-efficacy judgments of university students in foreign language tutoring. The Modern Language Journal, 94(4), 618-635. https://doi.org/10.1111/j.1540-4781.2010.01057.x

Meece, J. L., Anderman, E. M., \& Anderman, L. H. (2006). Classroom goal structure, student motivation, and academic achievement. Annual Review of Psychology, 57(1), 487-503. https://doi.org/10.1146/annurev. psych.56.091103.070258

Mills, N., Pajares, F., \& Herron, C. (2007). Self-efficacy of college intermediate French students: Relation to achievement and motivation. Language Learning, 57(3), 417-442. https://doi.org/10.1111/j.14679922.2007.00421.x

Ngo, H., Spooner-Lane, R., \& Mergler, A. (2017). A comparison of motivation to learn English between English major and non-English major students in a Vietnamese university. Innovation in Language Learning and Teaching, 11(2), 188-202. https://doi.org/10.1080/17501229.2015.1094076

Ngoc Truong, T. N., \& Wang, C. (2019). Understanding Vietnamese college students' self-efficacy beliefs in learning English as a foreign language. System, 84, 123-132. https://doi.org/10.1016/j.system.2019.06.007

Omari, O., Moubtassime, M., \& Ridouani, D. (2018). Assessing Moroccan university students' English learning motivation: A comparative study. Advances in Language and Literary Studies, 9(1), 81-88. https://doi. org/10.7575/aiac.alls.v.9n.1p.81

Pajares, F. (1996). Self-efficacy beliefs and mathematical problem-solving of gifted students. Contemporary Educational Psychology, 21(4), 325-344. https://doi.org/10.1006/ceps.1996.0025

Pajares, F. (2002). Gender and perceived self-efficacy in self-regulated learning. Theory into Practice, 41(2), 116125. https://doi.org/10.1207/s15430421tip4102_8

Pajares, F., \& Graham, L. (1999). Self-Efficacy, motivation constructs, and mathematics performance of entering 
middle school students. Contemporary Educational Psychology, 24(2), 124-139. https://doi.org/10.1006/ ceps.1998.0991

Pintrich, P. R. (1994). Student motivation in the college classroom. In K. W. Prichard \& R. M. Sawyer (Eds.), Handbook of college teaching: Theory and applications (Issue 2, pp. 23-43). Greenwood Press.

Raoofi, S., Tan, B. H., \& Chan, S. H. (2012). Self-efficacy in second/foreign language learning contexts. English Language Teaching, 5(11), 60-73. https://doi.org/10.5539/elt.v5n11p60

Schunk, D. H. (1991). Self-efficacy and academic motivation. Educational Psychologist, 26(3-4), 207-231. https:// doi.org/10.1080/00461520.1991.9653133

Schunk, D. H. (1995). Self-efficacy, motivation, and performance. Journal of Applied Sport Psychology, 7(2), 112137. https://doi.org/10.1080/10413209508406961

Schunk, D. H. (2012). Learning theories : An educational perspective (6th ed.). Pearson Education, Inc.

Schunk, D. H., \& Pajares, F. (2009). Self-efficacy theory. In K. R. Wentzel \& A. Wigfield (Eds.), Handbook of motivation at school (pp. 35-53). Taylor and Francis.

Silvia, P. J. (2003). Self-efficacy and interest: Experimental studies of optimal incompetence. Journal of Vocational Behavior, 62(2), 237-249. https://doi.org/https://doi.org/10.1016/S0001-8791(02)00013-1

Slimani, K., Messoussi, R., Bourekkadi, S., \& Khoulji, S. (2017). An intelligent system solution for improving the distance collaborative work. 2017 Intelligent Systems and Computer Vision, ISCV 2017, 1-4. https://doi. org/10.1109/ISACV.2017.8054987

Stankov, L., Morony, S., \& Lee, Y. P. (2014). Confidence: The best non-cognitive predictor of academic achievement? Educational Psychology, 34(1), 9-28. https://doi.org/10.1080/01443410.2013.814194

Sun, T., \& Wang, C. (2020). College students' writing self-efficacy and writing self-regulated learning strategies in learning English as a foreign language. System, 90, 102221. https://doi.org/https://doi.org/10.1016/j. system.2020.102221

Tracey, T. J. G. (2002). Development of interests and competency beliefs: A 1-year longitudinal study of fifth-to eighth-grade students using the ICA-R and structural equation modeling. Journal of Counseling Psychology, 49(2), 148-163. https://doi.org/https://doi.org/10.1037/0022-0167.49.2.148

Tracey, T. J. G., \& Hopkins, N. (2001). Correspondence of interests and abilities with occupational choice. Journal of Counseling Psychology, 48(2), 178-189. https://doi.org/https://doi.org/10.1037/0022-0167.48.2.178

Usher, E. L., \& Pajares, F. (2006). Sources of academic and self-regulatory efficacy beliefs of entering middle school students. Contemporary Educational Psychology, 31(2), 125-141. https://doi.org/10.1016/j. cedpsych.2005.03.002

Usher, E. L., \& Pajares, F. (2008a). Sources of self-efficacy in school: Critical review of the literature and future directions. Review of Educational Research, 78(4), 751-796. https://doi.org/10.3102/0034654308321456

Usher, E. L., \& Pajares, F. (2008b). Self-efficacy for self-regulated learning: A validation study. Educational and Psychological Measurement, 68(3), 443-463. https://doi.org/10.1177/0013164407308475

Van Dinther, M., Dochy, F., \& Segers, M. (2011). Factors affecting students' self-efficacy in higher education. Educational Research Review, 6(2), 95-108. https://doi.org/10.1016/j.edurev.2010.10.003

Vogt, C. M., Hocevar, D., \& Hagedorn, L. S. (2007). A social cognitive construct validation: Determining women's and men's success in engineering programs. The Journal of Higher Education, 78(3), 337-364. https://doi.org/ 10.1080/00221546.2007.11772319

Vuong, M., Brown-Welty, S., \& Tracz, S. (2010). The effects of self-efficacy on academic success of first-generation college sophomore students. Journal of College Student Development, 51(1), 50-64. https://doi.org/10.1353/ csd.0.0109

Wang, C., Schwab, G., Fenn, P., \& Chang, M. (2013). Self-Efficacy and self-regulated learning strategies for English language learners: Comparison between Chinese and German college students. Journal of Educational and Developmental Psychology, 3(1), 173-191. https://doi.org/10.5539/jedp.v3n1p173

Weda, S., Samad, I. A., Patak, A. A., \& Fitriani, S. S. (2018). The effects of self-efficacy belief, motivation, and learning strategies on students' academic performance in English in higher education. The Asian EFL Journal, 20(9.2), 140-168.

Yoestara, M., \& Putri, Z. (2019). Gender and language course participation differences in the university students' self-efficacy of TOEFL. Journal of Physics: Conference Series, 1232(1), 1-7. https://doi.org/10.1088/1742$6596 / 1232 / 1 / 012035$

Zajacova, A., Lynch, S., \& Espenshade, T. (2005). Self-efficacy, stress, and academic success in college. Research in Higher Education, 46(6), 677-706. https://doi.org/10.1007/s11162-004-4139-z

Zimmerman, B. J. (2000). Self-Efficacy: An essential motive to learn. Contemporary Educational Psychology, 25(1), 82-91. https://doi.org/10.1006/ceps.1999.1016 
Zimmerman, B. J., Bandura, A., \& Martinez-Pons, M. (1992). Self-motivation for academic attainment: The role of self-efficacy beliefs and personal goal setting. American Educational Research Journal, 29(3), 663-676. https://doi.org/10.3102/00028312029003663

Zimmerman, B. J., \& Martinez-Pons, M. (1988). Construct validation of a strategy model of student self-regulated learning. Journal of Educational Psychology, 80(3), 284. 


\section{APPENDIX}

\section{SELF-EFFICACY ITEMS AND THEIR MEANS WITHIN EACH UNIVERSITY}

\begin{tabular}{|c|c|c|c|c|}
\hline Self-Efficacy Items & University & $\mathbf{N}$ & Mean & Std. Deviation \\
\hline \multicolumn{5}{|l|}{ HOW WELL CAN YOU: } \\
\hline \multirow{4}{*}{ 1. Finish homework by the deadlines? } & MIU & 116 & 3.35 & 0.83 \\
\hline & SMBAU & 139 & 3.33 & 0.93 \\
\hline & AUI & 110 & 3.96 & 1.00 \\
\hline & Total & 365 & 3.55 & 0.92 \\
\hline \multirow{4}{*}{ 2. Study when there are other interesting things to do? } & MIU & 116 & 2.95 & 0.99 \\
\hline & SMBAU & 139 & 2.99 & 1.02 \\
\hline & AUI & 110 & 3.08 & 1.03 \\
\hline & Total & 365 & 3.01 & 1.01 \\
\hline \multirow{4}{*}{ 3. Concentrate on class subjects? } & MIU & 116 & 3.90 & 0.92 \\
\hline & SMBAU & 139 & 3.84 & 1.07 \\
\hline & AUI & 110 & 3.69 & 0.83 \\
\hline & Total & 365 & 3.81 & 0.94 \\
\hline \multirow{4}{*}{ 4. Take class notes? } & MIU & 116 & 4.04 & 0.96 \\
\hline & SMBAU & 139 & 3.85 & 0.94 \\
\hline & AUI & 110 & 3.78 & 1.15 \\
\hline & Total & 365 & 3.89 & 1.01 \\
\hline \multirow{4}{*}{$\begin{array}{l}\text { 5. Use the library/internet to get information for class } \\
\text { assignments? }\end{array}$} & MIU & 116 & 3.68 & 1.24 \\
\hline & SMBAU & 139 & 3.71 & 1.08 \\
\hline & AUI & 110 & 3.79 & 1.12 \\
\hline & Total & 365 & 3.73 & 1.15 \\
\hline \multirow{4}{*}{ 6. Plan and organize your classwork? } & MIU & 116 & 3.37 & 1.07 \\
\hline & SMBAU & 139 & 3.41 & 1.08 \\
\hline & AUI & 110 & 3.34 & 0.99 \\
\hline & Total & 365 & 3.37 & 1.04 \\
\hline \multirow{4}{*}{ 7. Remember information presented in class and textbooks? } & MIU & 116 & 3.52 & 0.95 \\
\hline & SMBAU & 139 & 3.59 & 0.88 \\
\hline & AUI & 110 & 3.81 & 0.78 \\
\hline & Total & 365 & 3.64 & 0.87 \\
\hline \multirow{4}{*}{ 8. Arrange a place to study without distractions? } & MIU & 116 & 3.60 & 1.22 \\
\hline & SMBAU & 139 & 3.27 & 1.18 \\
\hline & AUI & 110 & 3.67 & 0.97 \\
\hline & Total & 365 & 3.51 & 1.12 \\
\hline \multirow{4}{*}{ 9. Motivate yourself to do classwork? } & MIU & 116 & 3.89 & 1.01 \\
\hline & SMBAU & 139 & 3.75 & 1.07 \\
\hline & AUI & 110 & 3.59 & 0.90 \\
\hline & Total & 365 & 3.74 & 0.99 \\
\hline \multirow{4}{*}{ 10. Participate in class discussions? } & MIU & 116 & 2.94 & 1.11 \\
\hline & SMBAU & 139 & 3.19 & 1.23 \\
\hline & AUI & 110 & 3.94 & 1.01 \\
\hline & Total & 365 & 3.36 & 1.12 \\
\hline
\end{tabular}

Note. AUI = Al Akhawayn University; SMBAU = Sidi Mohamed Ben Abdellah University; MIU = Moulay Ismail University. 